\title{
ENSINO E APRENDIZAGEM DA RESISTÊNCIA A PARTIR DO FILME “O ANO EM QUE MEUS PAIS SAÍRAM DE FÉRIAS”
}

\section{TEACHING AND LEARNING RESISTANCE FROM THE FILM" THE YEAR MY PARENTS WENT ON VACATION"}

\author{
D Hiran Pinel \\ Doutor em Psicologia \\ Universidade Federal do Espírito Santo - UFES. \\ Vitória, Espírito Santo - Brasil. \\ hiranpinel@gmail.com \\ Rodrigo Bravin \\ Mestre em Educação \\ Universidade Federal do Espírito Santo - UFES. \\ Vitória, Espírito Santo - Brasil. \\ rodrigobravin@gmail.com \\ (iD) Menderson Rezende de Moura \\ Especialista em Educação Especial e Inclusiva \\ Universidade Federal do Espírito Santo - UFES. \\ Vitória, Espírito Santo - Brasil. \\ professormenderson@gmail.com
}

Resumo: O objetivo dessa pesquisa é descrever compreensivamente os modos de ser resistente do jovem Mauro que é o protagonista do filme "O ano em que meus pais saíram de férias" e trata do período em que o Brasil viveu a ditadura militar (1964-1985), focando no ano de 1970. Adotou-se como perspectiva metodológica a fenomenologia, tendo como referência o envolvimento existencial e o distanciamento reflexivo (FORGHIERI, 2012) com o filme, transcrição das falas e descrição das nossas compreensões. Mauro, diante dos outros, como ser-no-mundo, acaba agindo, na sua infância, contra o estabelecido, produzindo um modo de resistência diante de um estado que controla e limita as liberdades individuais, além de conviver com a distância do pai e da mãe e também com a morte de seu avô.

Palavras-chave: resiliência; resistência; ditadura; ser-no-mundo.

Abstract: The aim of this research is to describe comprehensively the ways of being resistant of the young Mauro who is the protagonist of the film "The year my parents went on vacation" and deals with the period in which Brazil lived the military dictatorship (1964-1985), focusing in the year 1970. Phenomenology was adopted as a methodological perspective, with reference to the existential involvement and reflective distance (FORGHIERI, 2012) with the film, transcription of the speeches and description of our understandings. Mauro, in front of others, as a being-in-the-world, ends up acting, in his childhood, against the established, producing a mode of resistance in the face of a state that controls and limits individual liberties, in addition to living with the distance of his father and of the mother and also with the death of his grandfather.

Keywords: resilience; resistance; dictatorship; being-in-the-world.

\section{Para citar - ABNT NBR 6023:2018}

PINEL, Hiran; BRAVIN, Rodrigo; MOURA, Menderson Rezende. Ensino e aprendizagem da resistência a partir do filme “o ano em que meus pais saíram de férias”. Cadernos de Pós-graduação, São Paulo, v. 20, n. 2, p. 165-174, jul./dez. 2021. Disponível em: https://doi.org/10.5585/cpg.v20n2.20229. 


\section{Introdução}

Há 57 anos começava a ditadura militar brasileira, oficialmente no dia 31 de março de 1964. No ano de 2014, boa parte do povo brasileiro estava vivendo e comentando os 50 anos dos "anos de chumbo", como também pode ser denominado o período que vai de 1964 até 1985, época em que o governo foi ocupado ditatorialmente por militares. Esse evento ainda é um espinho na carne do brasileiro, uma dor encarnada.

A interrogação é: como esse período - especificamente o ano de 1970 - pode ser compreendido no processo de ensino e aprendizagem da resistência? $\mathrm{O}$ ato de resistir será compreendido como um dos "modos de ser sendo junto com o outro no mundo" contra a ditadura militar brasileira pós-64, tendo como base o cotidiano do garoto Mauro, de 12 anos de idade, personagem do filme $O$ ano em que meus pais saíram de férias (BRASIL, 2006, direção de Cao Hamburguer).

O interesse deste artigo é o de produzir uma das muitas compreensões do filme, inventando uma produção discursiva, trazendo a lume a vitalidade dessa obra de arte para o entendimento de como é construído socio-historicamente os modos de ser resistente do protagonista Mauro - não objetivando dar uma resposta única e definitiva. Também poderá auxiliar aos professores (destacando o de História, Geografia e Sociologia, mas não só) e aos educadores sociais que trabalham com a feitura de diversas formas de resistir aos tempos sombrios como acontece quando se está sob a égide de ditaduras, de diversas repressões do Estado, quase sempre marcadas pelo clima psicossocial de medo e de sentimentos persecutórios. A proposta é a de produzir compreensão (pelo discurso) sobre essa película, e sugerir ao leitor professor (e a outros interessados pela temática) a procurar encontrar possíveis caminhos escolares (e educacionais) para a utilização dessa obra de arte.

O fato é que não se pode desprezar o papel de um filme nas subjetividades e nas disputas políticas. Eles são uma série de imagens impressas em suporte específico, alinhadas em sequência, chamadas fotogramas. Essas imagens são projetadas de forma rápida e sucessiva, dando ao espectador a ilusão de observar movimentos, enxergá-los - de ser tocado por eles, como no real, em um efeito psicológico chamado "movimento beta". A cintilação entre os fotogramas não é sentida pela percepção devido a um efeito conhecido como "persistência da visão", isto é, o olho humano retém uma imagem durante uma fração de segundo após a sua fonte ter saído do campo da visão.

Entretanto, o cinema é acima de tudo um artefato cultural. Ele é produzido considerando cada cultura que se coloca na tela - projeta-se. Ao mesmo tempo em que afeta a cada um, cada um o afeta também. É uma arte de muito significado, pois provoca entretenimento popular e pode 
destinar-se, mesmo que não explicitamente, a educar, podendo, assim, ser uma maquinaria de influenciar os cidadãos.

Provas indicam que o cinema nasceu em Paris, em dezembro de 1895, no dia 28. Os irmãos Lumière fizeram uma apresentação pública do hoje filme cult: o curta L'Arrivée d'un Train à La Ciotat. Eles estavam lançando um produto de seus inventos, o cinematógrafo. Havia apenas uns trinta e poucos presentes na sala escura, mas foi o suficiente para a notícia socializar. Em pouco tempo, emergiria uma indústria chamada cinema, um recurso que provoca o fazer artístico e pode evocar mudanças nas nossas interioridades/subjetividades na objetividade do mundo.

\footnotetext{
Em 1896, chegaram ao Rio de Janeiro aparelhos de projeção cinematográfica. Já em 1898 foram realizadas as primeiras filmagens no Brasil. Somente em 1907, com o advento da energia elétrica industrial na cidade, o comércio cinematográfico começou a se desenvolver. Nessa fase predominaram filmes de reconstituição de fatos cotidianos, e, a partir de 1912, das mãos de Francisco Serrador, Antônio Leal e dos irmãos Botelho é que começaram a ser produzidos filmes com menos de uma hora de projeção [...] (TURMA 517 ARTES VISUAIS, 2013, p. 01).
}

Dessa época surgia a problemática do cinema nacional: a de enfrentar o domínio no mercado interno do cinema estadunidense. Na história do cinema brasileiro, encontra-se diversos movimentos, mas o foco aqui-agora é no período pós-64 denominado "anos de chumbo" ou a ditadura militar, que começa oficialmente em 31 de março de 1964 e termina no dia 15 de janeiro de 1985. Em 2014, completaram-se 50 anos desse movimento acontecido também em nome do empresariado nacional e internacional.

Naquele período, floresceu o movimento denominado "cinema novo", com marcas bem brasileiras (mas não só), destacando dele, por exemplo, o cineasta Glauber Rocha - que resistiu à censura muito forte do período que era sempre acompanhada de violência física e psicológica. Também emerge - com uma censura mais afrouxada - o movimento da pornochanchada influenciado por alguns filmes italianos, donde há muitas piadas, o bom humor e a insinuação (apenas isso) de práticas sexuais.

Glauber Rocha em Deus e o Diabo na Terra do Sol (1964) produziu uma cena antológica quando o personagem rodopiando declara que "mais fortes são os poderes do povo" - uma subversão à censura. Já outro diretor, Roberto Farias, copia essa cena (com a mesma frase), trazendo em outro sentido (mas ainda assim mantendo algo da origem), em 1968, no filme RC, em ritmo de aventura, prenunciando o cantor Roberto Carlos que após a frase (dita pelo ator Reginaldo Farias) irá interpretar no terraço de um alto edifício de São Paulo a canção popular "Quando". É importante destacar que alguns artistas se insurgiram, de diversos modos de ser, ao estabelecido pela 
ideologia dominante de então. Não ocorreu apenas alienação em tempos sombrios, mas também resistências e resiliências.

O cinema brasileiro tem desvelado seu interesse por esses "anos de chumbo" brasileiros, pela ditadura. E o foco aqui-agora será para a obra de arte filmica intitulada $O$ ano em que meus pais sairam de férias.

\section{Sinopse do filme}

Ano de 1970, vive-se em um Brasil ainda sob a égide do Governo Militar - ditatorial. Ano marcado pela censura prévia das artes e letras (e até científica, dependendo do tema e teoria estudados), pelo tricampeonado obtido pelo país na Copa do Mundo, pela euforia da construção da Transamasônica, sob a égide do Programa de Integração Nacional, pelo clima paranóico desvelado no assassinato de Carlos Lamarca. É século XX.

Mauro, produzido no seu tempo/espaço, adora futebol e jogo de botão (de futebol). Ele tem sua vida mudada completamente, já que seus pais “saem de férias" de forma inesperada e sem motivo aparente. Segundo a sua própria percepção, que por sinal vai se constituindo em um projeto de ser presença da resistência, os pais ficam presentes como ensinantes de resiliência disponíveis a um hábil (e disposto) filho aprendente. "Parece então que presença é, antes de tudo, envolver-se com a realidade. Deste modo, quanto mais me envolvo com a realidade, mais presente estou em mim e para mim" (RIBEIRO, 2006, p. 163).

$\mathrm{Na}$ verdade, os pais de Mauro foram obrigados a fugir do país por serem militantes da esquerda que agiam contra a ditadura militar de então. Eles estavam sendo perseguidos pelo Estado, e por essa razão decidiram deixá-lo com o avô paterno chamado Mótel- um barbeiro de origem judaica, que mora em São Paulo. Porém, o avô falece no mesmo dia em que Mauro chega. Esse evento de dor e de abandono faz com que ele tenha que ficar perambulando pelo prédio, rodeando a porta do apartamento do avô - até ser acolhido por Shlomo, um velho judeu solitário, que é vizinho de Mótel, e que já sabe da morte dele.

Enquanto aguarda um telefonema dos pais (que retornariam das "férias"), Mauro precisa lidar com sua nova realidade, com momentos de tristeza pela situação em que tem que viver e também de alegria, ao acompanhar o desempenho da seleção brasileira na Copa do Mundo de 1970, brincar com os novos amigos, indicando, assim, uma convivência criativa e provocadora no bairro Bom Retiro de São Paulo, que é um espaço multicultural, com pessoas de diversas origens, principalmente italianas, judaicas, gregas, coreanas e, mais recentemente, bolivianas, além do comércio local ser administrado, em sua maioria, por coreanos. 


\section{Modos de ser resistente}

Intencionalmente, dividiu-se aqui o filme em três partes, que no experienciamento da obra de arte acontece de modo indissociado: $1^{a}$ - Esperando o pior; $2^{a}$ - Negro e voador; $3^{\mathrm{a}}$ - O Outro e o ensino-aprendizagem. Essas partes já indicam os modos de ser de Mauro e sua entrega aos ensinamentos advindos dos outros acerca da resistência.

\section{Esperando o pior}

Mauro está em Belo Horizonte e os pais angustiados com a perseguição procuram encontrar saída com quem deixar o filho. Mauro não tem muita clareza do que se passa no país, mas se desvela sempre cuidadoso consigo mesmo, com o outro e as coisas do mundo - como muita gente naquele período não o tinha devido às fortes repressões. Ele cuida do seu jogo de botões, está interessado na Copa do Mundo e tem seus ídolos naqueles times. Ele tem uma relação carinhosa com a mãe e com o pai, que é marcante em sua vida.

No caminho de ida pra São Paulo, ele se interessa pelo futebol e pelas "fofocas" na área: por que Pelé não pode jogar com Tostão? O pai considera por menos e fala que isso é invenção da imprensa para desviar a atenção de outros temas. Nessa trajetória, caminhões do Exército estão nas estradas - produzindo, assim, sentimentos de que alguém está por perto a vigiar e a punir, caso subvertam a ordem estabelecida como a única correta. O clima é, então, de paranoia, advinda do medo, que dá bem a dimensão de "a quantas andavam” os sentimentos persecutórios.

Ao chegar a São Paulo, Mauro descobre que o avô Mótel morreu. Passa a ser cuidado por Shlomo, que é judeu. Assim, começa a se esboçar um contexto de diversidade (e de diferenças), um espaço-tempo que ensina o respeito, a tolerância, a permissão, a invenção, a criação - a resistir à tristeza, colocando em seu lugar a alegria marcada pela esperança.

Os amigos se configuram parceiros e curiosos. A sexualidade transborda. Novas descobertas de ser no mundo. Todas essas variáveis dão a dimensão do seu poderio em ensinar ser resistente.

Havia a repressão intelectual, corporal... Mas, por outro lado, havia resistência, oposição ao estabelecido, e isso se desvelava de diversos modos. É capturar que os brasileiros não foram tão submissos assim à Ditadura Militar. Mauro, nos seus modos ainda de ser criança em tempos sombrios, era provocador (e produtor) de modos de resistência.

O filme foca em Mauro e o mundo ao redor, a sua oposição a deixar-se contaminar pela tristeza, uma resistência que ele cria para si, algo que aproxima ao dos pais foragidos. Mesmo o clima e a cultura da ditadura não afastam Mauro de sua perspectiva. 
É aí - nesse terror do Estado - que Mauro se identifica em ser goleiro - um "salva(dor) da pátria” e ao mesmo tempo, que por bem defender, tornar-se uma espécie de herói. O futebol, como obra de arte, que produz relaxamento pela alegria, cuja poética pode iluminar essa fato: "Qualquer amor já é um pouquinho de saúde, um descanso na loucura [...]” (ROSA, 1994, p. 141).

$\mathrm{Na}$ sua solidão de menino (um forte), advinda também pelo abandono estatal e pelos pais (expulsos pelo Estado), espera sempre o pior - pois, a todo tempo, Mauro espera que ele impeça o gol ou que permita o gol aparecer de sentido - de qualquer jeito sempre haverá um grupo de fãs que irão criticar e/ou elogiar. Mauro, como joga(dor), joga com criatividade com sua (nossa) dor.

Essa solidão (do goleiro, que agora é Mauro) é construída nesse tempo e nesse espaço uma Ditadura de modo geral produz angústias de que "alguém acompanha meus passos" a fim de me punir. É uma das características desse período; a de produzir (e inventar) os medos em geral, específicos públicos (se posicionar enquanto cidadão crítico) e privados (medo de amar; medo de dizer o que pensa dentro da família, medo da expressão sexual, medo do prazer e da alegria, culpa após sentir-pensar-agir ousados e criativos, mas percebidos como maléficos etc.). Mauro entregase à alegria, e isso parece ser um dos fatores do existir de seu modo de ser resistente.

\section{Negro e voador}

Ser goleiro é uma meta carregada desde o início do filme - é o desejo do menino. A película tem essa narrativa in off logo no começo: "Meu pai diz que no futebol todos podem falhar, menos o goleiro. Eles são jogadores diferentes, porque passam a vida ali, esperando o pior” (diz Mauro). Por isso, ele desvela que gostaria de ser negro e voador - um goleiro assim.

Mauro, chegando a São Paulo, na sua aparente representação social do goleiro psicossocialmente definida por seu pai (um sujeito que vive ali no espaço tempo do gol, esperando o pior), não está totalmente só - há um grupo de participantes à sua espera. Traz o pai em sua memória, que ganha mais sentido quando ele brinca sério com o jogo de botões. Logo, ele será acolhido por Shlomo, um idoso que substituíra seu avô falecido. Inclusive, será esse novo parceiro (companheiro) que provocará a solidão ao levá-lo ao enterro de Mótel.

Shlomo dará alimentação ao menino (ou articulará isso), colocará limites (respeito aos símbolos judaicos, por exemplo), dará a ele oportunidade de acordar por meio de banhos frios etc. Mesmo recorrendo à lembrança do avô (a famosa cena da luva), é Shlomo que fará essa mediação.

Contrapondo a um mundo adulto, haverá Hanna, a menina que tem um negócio lucrativo: levar Mauro e coleguinhas a adentrar a um porão, que pelas frestas na parede, ele (e seus colegas) poderão ver do outro lado mulheres bonitas ou não tanto, que ao experimentarem vestidos da 
costureira, precisam fazer uma espécie de strip-tease. O desnudamento seduz os meninos, enquanto Hanna fica atenta ao dinheiro recebido de cada um deles.

Há ainda uma bela (e generosa) jovem Irene, objeto de desejo dos meninos, que ganha volume pelo escopismo, um desejo de ver, de olhar - "olho que vê também tem prazer de ver" (HASSAN, 2008, p. 2). A delícia do olhar em olhar de sentido. Ela se dedica afetivamente a Mauro, entendendo sua solidão e angústia frente à ausência do pai e da mãe. A moça tem um namorado que não os ameaça - ao contrário, ele é o modelo masculino do desejante, pois conseguiu "chegar lá" no amor, e o desejo deles é amar também - um amor que começa no sexo e que se amplia simplesmente para o amor. Irene é suave como a noite e pela generosidade funciona como uma ensinante das delicadezas do amor - e o amor pode ser uma variável do ato de resistir. Tudo se insinua - apenas isso -, mas será aí que o vital para Mauro, naqueles momentos, é entregar-se ao amor. O amor mediando seu desenvolvimento e aprendizagem junto ao outro no mundo.

São, assim, muitos ensinamentos e aprendizagens na/da e com a vida cotidiana na aprendizagem da resistência.

\section{O outro e o ensino-aprendizagem}

A construção do eu acontece sempre pelo outro - alteridade, outridade. Em Paulo Freire, concorda-se que o ser humano é subjetividade (TROMBETTA, 2012), mas esta se constrói (e se efetiva) na relação dialógica com o outro, na intersubjetividade - minha experiência com a outra experiência no mundo, interexperiência. "Seguindo o legado ético-pedagógico de Freire, podemos concluir dizendo que o resgate da dignidade do outro, da sua alteridade é condição primeira para a edificação de um projeto mundo-sociedade em que seja menos difícil amar" (TROMBETTA, 2012, p. 34). Freire (1996) aponta que a desumanização deforma a vocação humana que é humanizar-se. Assim, Mauro se desvela aprendendo por essa abertura ao outro que se põe à sua frente e o provoca a crescer.

$\mathrm{Na}$ cena em que o fundo musical é a canção popular "Eu sou Terrível" (CARLOS; CARLOS, 1970), há uma conotação simbólica desse aprender diante do outro no cotidiano - ser terrível no sentido de maravilhoso, de enfrentar, de ser provocador do cotidiano. Mauro dança desse rock tupiniquim - que se denominava de iê-iê-iê. Ele está bailando com uma menina, mas seu olhar desejante vai se desviando para Hanna, percebida como uma mulher concreta ali - ele é terrível, e é bom parar e desse jeito lhe provocar. Hanna está sentada delicadamente, e é ótima empresária.

Naquele espaço-tempo, mostram-se os elementos da aprendizagem em Paulo Freire (1996): o encontro (em um sentido comum - o bom encontro); a escuta e o diálogo com o outro, o diálogo 
"enquanto concepção que fundamenta a condição existencial dos seres humanos [...]" (MENDONÇA, 2008, p. 122). Com esses elementos básicos (tem mais) destaca-se uma ação de reconhecer-se no outro si mesmo (no mundo) que media a criação e invenção (produção) do amor pelo outro (e por si) - um começo de luta pela justiça pela expressão da consciência crítica. Tomando o final dessa obra de arte, Mauro já pontua, dentro de sua idade, descobertas que estão desvelando o surgimento desse modo de ser sendo crítico: "E assim foi o ano de 1970. O Brasil virou tricampeão mundial. E mesmo sem querer, nem entender direito, eu acabei virando uma coisa chamada exilado" (fala do personagem). Ele é terrível e, sendo provocado, ele nem tem medo do perigo parafraseando a letra da canção de Roberto. Dança expressivamente em movimentos alegres, ensinando a importância disso, contagiando seus iguais naquela dança (dançinha numa tarde de domingo) - eis um corpo que fala em resistir, em se opor às repressões contra o corpo; uma ação contra o corpo docilizado e submetido.

Mauro, diante dos outros, como ser-no-mundo, acaba agindo, na sua infância, contra o estabelecido, produzindo um modo de resistência. Resistir é uma prática que ele viveu desde Belo Horizonte, bem como agora ali, no bairro do Bom Retiro - que se opõe no filme ao não diálogo da Ditadura: "Nas relações nas quais não há diálogo, há imposições, narrativas, dissertações que um sujeito impõe a uma pessoa vista, por ele, como objeto" (LOUREIRO, 2009, p. 37). Mais ainda, Freire (2005) enfatiza o poder do diálogo como instrumento que revela o mundo e que possibilita sua desconstrução e resconstrução.

\footnotetext{
A existência, porque humana, não pode ser muda, silenciosa, nem tampouco pode nutrirse de falsas palavras, mas de palavras verdadeiras, com que os homens transformam o mundo. Existir, humanamente, é pronunciar o mundo, é modificá-lo. O mundo pronunciado, por sua vez, se volta problematizado aos sujeitos pronunciantes, a exigir deles novo pronunciar (FREIRE, 2005, p. 90).
}

O acolhimento individual de Shlomo é pura alteridade e uma ação política em temposespaços sombrios advindos do Estado brasileiro. Quando um acolhe, o mundo desumanizado se humaniza em microcosmos de pessoas e grupos (e até instituições). Fato é que a comunidade judaica - com todas as dificuldades de funcionamento de um grupo, as contradições de ser da alteridade - acolhe Mauro, interessa-se por ele. O militante Ítalo (outro personagem) pratica isso perfeitamente - há interesse sincero pelo outro. Um aprender a resistir por meio do outro, tornando-se Ítalo um "exemplo daqueles que arriscaram a própria vida na luta contra o regime militar" (ANSARA, 2009, p. 283). Outros personagens além dos pais e de Ítalo, como Daniel e Bia - recorrendo a Ansara -, podem ser mostrados como heróis advindos da “[...] riqueza da organização popular" (ANSARA, 2009, p. 283). 
O ato de ensinar nesse mosaico complexo de ser da alteridade, "não é transferir conhecimentos, mas criar possibilidades para a sua produção ou sua construção" (FREIRE, 1996, p. 25). Trata-se do ensinar-aprender (vividos numa dinâmica inter-relação) de um movimento complexo, sensível - concreto. Isso indica que não é possível ensinar sem aprender, e o autor destaca: "Quem ensina aprende ao ensinar e quem aprende ensina ao aprender". (FREIRE, 1996, p. 25).

Sendo algo de ser-no-mundo, próprio do homem, não produz estranheza sentir todos os personagens do filme nesses movimentos que têm suas contradições. A criança lucra com os adultos à sua volta, assim como obtém benefícios nesse processo relacionando-se com os coleguinhas - há isso nas linguagens orais e comportamentais (e subjetivas) mediado pelos bons encontros, escutas, diálogos (verbais e expressivos gerais).

Mediados pelo mundo, os personagens como o de Mauro são ensinados (e aprendem) em um processo focal (e maior) qual seja: o de conhecer. E nesse processo de aula não escolar (e informal), o mundo-aula, os sujeitos ensinantes e aprendentes são mutuamente implicados. Em estando junto ao outro no mundo, Mauro percebe que os conteúdos aprendidos não são sólidos e muito menos verdades únicas - a postura dele é de se entregar ao outro, às novidades que surgem na alteridade. A procura pelo pai, os telefonemas, a morte do avô - são situações vividas prenhes de fragilidades, de insegurança, de angústia. $O$ vivido é dele, mas é uma experiência brasileira da época retratada no filme: as consequências da ditadura, da repressão. Mas, ao mesmo tempo, é sua urgência em resistir a isso, e mesmo desvelar-se resiliente.

\section{(In) conclusões}

O objetivo dessa pesquisa foi descrever compreensivamente os modos de ser resistente do jovem Mauro que é o protagonista do filme "O ano em que meus pais saíram de férias" e trata do período em que o Brasil viveu a ditadura militar (1964-1985).

Nesse período, pode-se compreender Mauro como resistente, cercado de resistentes inventivos e criativos, e mais: gente que nas simbólicas barricadas produzem eventos de oposição, de enfrentamento - e recebendo as consequências de um Estado militar ditatorial. Foi usado como exemplo a dancinha na qual o menino se assume aberto às novas expressões, dança freneticamente e, não apenas isso, ao ensinar com efetividade, os outros (de si) se envolvem existencialmente com os balanços - somos terríveis, e é bom parar, e desse jeito nos provocar, não é preciso nem avião, eu voo mesmo daqui do chão.

Mauro, ao se conectar com a fala de seu pai sobre os goleiros, assumiu, diante das drásticas mudanças em sua vida, a posição de lutar contra a desumanização promovida pelo regime militar 
e, assim, produzir horizontes existenciais mais belos, marcados pela solidariedade. Esse contexto se conecta com a perspectiva freireana que indica os seres humanos como responsáveis por sua humanização, num processo contínuo de busca do ser mais.

A resistência de Mauro diante das vicissitudes da vida o faz, também, um ser da esperança que se move com a crença de que é possível, a partir de seu cotidiano, inventar possibilidades de existir, acreditando, como afirma Guilherme Arantes, que "amanhã será um lindo dia da mais louca alegria que ser possa imaginar”.

\section{Referências}

ANSARA, Soraia. Memória política, repressão e ditadura no Brasil. Curitiba: Juruá, 2009.

CARLOS, Roberto; CARLOS, Erasmo. Eu sou terrivel. CD de Roberto Carlos, 1970. Música popular.

DA criação do cinema no mundo, o cinema mudo e o cinema no Brasil. Turma 517 de Artes Visuais, 2013. Disponível em: http://artesvisuais517.blogspot.com/. Acesso em: 09 jun. 2021.

FORGHIERI, Yolanda Cintrão. Psicologia fenomenológica: fundamentos, método e pesquisas. São Paulo: Cengage Learning, 2012.

FREIRE, Paulo. Pedagogia da autonomia: saberes necessários à prática educativa. Rio de Janeiro: Paz e Terra, 1996.

FREIRE, Paulo. Pedagogia do oprimido. Rio de Janeiro: Paz e Terra, 2005.

HASSAN, Sara Elena. Pintores e poetas no roteiro da pulsão escópica: anotações preliminares. Caligrama (São Paulo. Online), 4(1), 2008.

LOUREIRO, Stefânie Arca Garrido. Educação humanista e diversidade: um diálogo possivel entre Paulo Freire e Martin Heidegger. Belo Horizonte: Nandyala, 2009.

MENDONÇA, Nelino Azevedo de. Pedagogia da humaniz̧ação: a Pedagogia bumanista de Paulo Freire. São Paulus, 2008.

RIBEIRO, Jorge Ponciano. Vade-mécum de gestalt-terapia: conceitos básicos. São Paulo: Summus, 2006.

ROSA, João Guimarães. Grande sertão veredas. São Paulo: Editora Nova Aguilar, 1994.

TROMBETTA, Sérgio. Alteridade. In: STRECK, Danilo Romeu et al. Dicionário Paulo Freire. Belo Horizonte: Autêntica, 2012. 